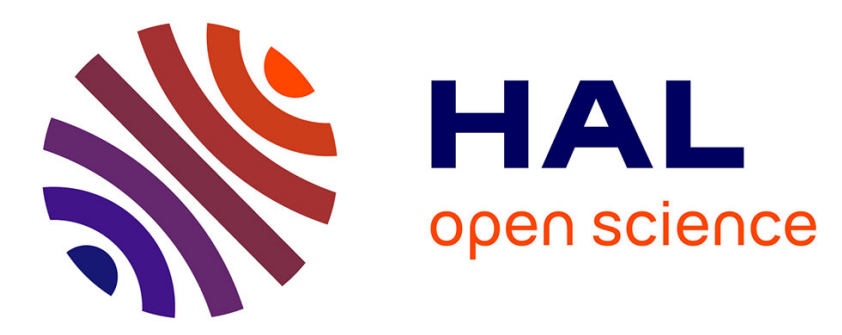

\title{
Recovery, structure and physicochemical properties of an aggregate-rich fraction from Acacia senegal gum
}

Rafael Apolinar Valiente, Pascale Williams, Michael Nigen, Véronica Mejia

Tamayo, Thierry Doco, Christian Sanchez

\section{- To cite this version:}

Rafael Apolinar Valiente, Pascale Williams, Michael Nigen, Véronica Mejia Tamayo, Thierry Doco, et al.. Recovery, structure and physicochemical properties of an aggregate-rich fraction from Acacia senegal gum. Food Hydrocolloids, 2019, 89, pp.864-873. 10.1016/j.foodhyd.2018.11.054 • hal-01981147

\section{HAL Id: hal-01981147 \\ https://hal.science/hal-01981147}

Submitted on 14 Jan 2019

HAL is a multi-disciplinary open access archive for the deposit and dissemination of scientific research documents, whether they are published or not. The documents may come from teaching and research institutions in France or abroad, or from public or private research centers.
L'archive ouverte pluridisciplinaire HAL, est destinée au dépôt et à la diffusion de documents scientifiques de niveau recherche, publiés ou non, émanant des établissements d'enseignement et de recherche français ou étrangers, des laboratoires publics ou privés. 


\title{
Recovery, structure and physicochemical properties of an aggregate-rich fraction from Acacia senegal gum
}

\author{
Rafael Apolinar-Valiente ${ }^{\mathrm{a}, *}$, Pascale Williams ${ }^{\mathrm{b}}$, Michaël Nigen ${ }^{\mathrm{a}}$, Veronica Mejia Tamayo ${ }^{\mathrm{a}}$, \\ Thierry Doco ${ }^{\mathrm{b}}$, Christian Sanchez ${ }^{\mathrm{a}}$ \\ ${ }^{a}$ UMR 1208 Ingénierie des Agropolymères et Technologies Emergentes, Montpellier SupAgro, INRA, Université de Montpellier, CIRAD, 2 Place Pierre Viala, 34060, \\ Montpellier Cedex 1, France \\ ${ }^{\mathrm{b}}$ UMR 1083 Sciences Pour l'OEnologie, INRA, Montpellier SupAgro, Université de Montpellier2, 2 Place Pierre Viala, 34060, Montpellier Cedex 1, France
}

\section{A R T I C L E I N F O}

\section{Keywords:}

Acacia senegal gum

Aggregates

Ion exchange chromatography

SEC-MALLS

Polysaccharides

Proteins

\begin{abstract}
A B S T R A C T
Acacia senegal gum (Asen) is a natural exudate of Acacia trees species largely used in food as well as other industries. This natural product appears as a continuum of molecular species which shows diverse sugar and protein composition, molar masses and charge density. The presence of larger macromolecules, or aggregates, has been demonstrated to have a great influence on the Acacia gum characteristics. The present work is designed to recover and characterize one protein-rich fraction presenting a high aggregate content. With this fraction we will open the door to future works with the aim to acquire a deeper knowledge about the origin and the role of the aggregates from Asen gum. Our methodology is based on the well-known ion exchange chromatography, using DEAE Sephacel gel as stationary phase. We have separated Asen into two different fractions (fraction IECF1 and fraction IEC-F2), being both of them confirmed as arabinogalactan-proteins (AGP) by Yariv detection. Fraction IEC-F1 has been thoroughly characterized (sugar and amino acid composition, molar mass distribution, weight-average molar mass, number-average molar mass, polydispersity index, intrinsic viscosity, radius of gyration, Mark-Houwink-Sakurada analysis, hydrodynamic radius, partial specific volume and partial specific adiabatic compressibility). From amino acid data, we have estimated that fraction IEC-F1 theoretically corresponds to about $70 \%$ of HIC-F3 and $30 \%$ of HIC-F2, respectively the second and the third fractions separated by hydrophobic interaction chromatography (HIC) and largely described in literature. The obtained information indicates that fraction IEC-F1 appears as a fraction highly rich in aggregates.
\end{abstract}

\section{Introduction}

Acacia gum, also known as gum Arabic, is a natural exudate of Acacia trees species, playing an important role in the plant defense (Nussinovitch, 2009). Acacia gum has been largely used from ancient times to the present day for different purposes such as food, pharmaceutical and other industries (reviewed by Sanchez et al., 2018). The most known Acacia gum is Acacia senegal (Asen) gum, which has been largely characterized in terms of composition (Idris, Williams, \& Phillips, 1998; Lopez-Torrez, Nigen, Williams, Doco, \& Sanchez, 2015; Renard, Lavenant-Gourgeon, Ralet, \& Sanchez, 2006) and structure (AlAssaf, Phillips, \& Williams, 2005; Islam, Phillips, Sljivo, Snowden, \& Williams, 1997; Verbeken, Dierckx, \& Dewettinck, 2003). Asen gum are hyperbranched polysaccharides rich in arabinose and galactose mainly formed by chains of 3,6-linked $\beta$-D-Galp substituted in position 6 by side chains of 3-linked $\alpha$-L-Araf. Akiyama, Eda, and Kato (1984) were the first who suggested that Acacia gum was a kind of arabinogalactanprotein (AGP). AGP show some defining characteristics: their protein moiety is ranged around 1 and $10 \%$ of the total mass, while approximately their $90 \%$ are type II arabinogalactan chains having the ability to bind to $\beta$-glucosyl Yariv phenylglycoside (Lamport \& Várnai, 2013; Tan et al., 2012). Besides, AGP are usually classified in hydroxyprolinerich superfamily of glycoproteins (Dickinson, 2003; Gleeson \& Jermyn, 1979).

Acacia gum appears as a continuum of molecular species presenting diverse protein/sugar ratios, molar masses and charge densities (Renard et al., 2006). It is possible to fractionate Acacia gum through different procedures, hydrophobic interaction chromatography (HIC) being the most used technique (Osman, Menzies, Williams, Phillips, \& Baldwin, 1993; Randall, Phillips, \& Williams, 1989; Ray, Bird,

\footnotetext{
* Corresponding author.

E-mail addresses: rafael.apolinar.valiente@gmail.com (R. Apolinar-Valiente), pascale.williams@inra.fr (P. Williams), michael.nigen@supagro.fr (M. Nigen), vero_tati@hotmail.com (V.M. Tamayo), thierry.doco@inra.fr (T. Doco), Christian.Sanchez@supagro.fr (C. Sanchez).
} 
Iacobucci, \& Clark, 1995; Renard et al., 2006). HIC gives three main AGP fractions: a major fraction ( $80-90 \%$ of total) historically named arabinogalactan-peptide (Fraction 1), which presents low protein content $(\sim 1 \%)$ and low mean molar mass $\left(2.8 \times 10^{5} \mathrm{~g} \mathrm{~mol}^{-1}\right)$, another highly polydisperse arabinogalactan-protein complex (Fraction 2) of high molar mass $\left(1 \times 10^{6}<\mathrm{M}_{\mathrm{w}}<4 \times 10^{6} \mathrm{~g} \mathrm{~mol}^{-1}\right)$ rich in protein ( $\sim 10 \%)$ and another arabinogalactan-protein complex (1-2\% of total gum) (Fraction 3) presenting the highest protein content $(-25 \%)$ and polydispersity (Renard et al., 2006). These three AGP fractions were also called HIC-F1, HIC-F2 and HIC-F3 (Mejia Tamayo et al., 2018) based on the used separation technique and the elution order of the fractions, remaining consistent with the fact that all the three fractions are identified as AGP.

AGP complexity arises from their composition, conformation and polydispersity (Mejia Tamayo et al., 2018), but also to their capacity to self-aggregate (Al-Assaf, Sakata, McKenna, Aoki, \& Phillips, 2009; Li et al., 2009). Several authors have found the existence of aggregates in Acacia gum (Dror, Cohen, \& Yerushalmi-Rozen, 2006; Lopez-Torrez et al., 2015) or in AGP fractions from Acacia gum (Al-Assaf et al., 2009; Pickles et al., 2007; Renard, Garnier, Lapp, Schmitt, \& Sanchez, 2012). Their differences towards aggregation in aqueous solution could be explained by their varying chemical composition, mainly their protein content and amino acid composition. Various works (Gashua, Williams, \& Baldwin, 2016; Renard et al., 2012) depicted the presence of aggregated structures by transmission electron microscopy. Aggregate chains can render the identification of single AGP macromolecules very difficult (Renard et al., 2012). Main causes of the aggregation process could involve strong hydrophobic interactions between amino acid side chains in the polypeptide component of the gum (Renard et al., 2012) and/or intermolecular H-bonds between the saccharide portions (Mahendran, Williams, Phillips, Al-Assaf, \& Baldwin, 2008). The protein-mediated aggregation processes appears as a key factor in the emulsifying properties (Castellani et al., 2010; Dumay, Picart, Regnault, \& Thiebaud, 2006) and also in the intrinsic ability to stabilize complex coacervate (Sanchez \& Renard, 2002). Mothe and Rao (1999) highlighted the shear-thinning behavior of Acacia gum solutions and assigned it to the presence of AGPs based micro-aggregates. Lopes, Andrade, Milas, and Rinaudo (1995) observed that the velocity of the particle sedimentation is affected by the type and size of the aggregates of welan gum. Manning and Bird (2015) found that aggregates could affect the Acacia gum fractionation through synthetic membranes. Aggregating Acacia gum through controlled Maillard reaction can improve its functional properties, the final product being called SUPER GUM ${ }^{\mathrm{TM}}$ (Al-Assaf, Phillips, Aoki, \& Sasaki, 2007). Moreover, aggregates can hinder gums analysis and the consequent data interpretation (Qian, Cui, Wang, Wang, \& Zhou, 2011) but also explain the observed discrepancies between the calculated and experimental $R_{H}$ values in HIC-F3 fraction (Renard et al., 2014a). In view of the above discussion about the importance of aggregates, we consider that more extensive studies are needed on this key matter. Therefore, it would be interesting to find a separation approach to recover only one protein-rich fraction presenting a high aggregate content to unravel the origin and nature (structure, size, anisotropy) of aggregates, their strong link with protein moiety and their impact on physicochemical properties of these AGPbased aggregates. Based on the work of Osman et al. (1995) about the fractionation of the AGP-aggregate rich Acacia gum by ion exchange chromatography (IEC), we selected and adapted their procedure trying to obtain our desired high aggregate-content fraction. We have hence fractionated Acacia gum by IEC using DEAE Sephacel gel as stationary phase. Subsequently, we have characterized the obtained fractions, analysing their sugar, amino acid composition and structure, including molecular parameters such as the weight average $\left(\mathrm{M}_{\mathrm{w}}\right)$ and number average $\left(M_{n}\right)$ molar masses, the radius of gyration $\left(R_{g}\right)$, the intrinsic viscosity $([\eta])$ and the polydispersity index $\left(\mathrm{M}_{\mathrm{w}} / \mathrm{M}_{\mathrm{n}}\right)$ to achieve a deeper knowledge of them. In summary, this work will provide and characterize one aggregate-rich fraction from Acacia senegal gum which will help for understanding the solution properties of the individual macromolecules families and their aggregates in solution.

\section{Material and methods}

\subsection{Material}

Acacia gum type from Acacia senegal trees located in Sudan (Lot: OF152413) was provided by ALLAND \& ROBERT Company - Natural and organic gums (Port Mort, France).

\subsection{Preparation of Acacia senegal gum (Asen) dispersions}

Asen dispersions were prepared by weight (wt \%). Known amounts of Asen powder (650 g, corresponding to $581 \mathrm{~g}$ in dry terms) were dispersed in water $(6500 \mathrm{~mL})$ and gently stirred for $24 \mathrm{~h}$ at room temperature $\left(20^{\circ} \mathrm{C}\right)$. The $\mathrm{pH}$ of dispersions was subsequently adjusted at 3.5 using $\mathrm{HCl} 1 \mathrm{~N}, \mathrm{HCl} 0.1 \mathrm{~N}$, or $\mathrm{NaOH} 0.5 \mathrm{~N}$ solutions.

\subsection{Ion exchange chromatography (IEC)}

IEC separation was performed at room temperature on DEAE Sephacel (Sigma Aldrich, St. Louis, Mo) column $(54 \times 20 \mathrm{~cm})$. The column was firstly equilibrated with degassed water. Dissolved Asen was loaded and eluted by water (around $10 \mathrm{~L}$ ) at a flow rate of $40 \mathrm{~mL} \mathrm{~min}^{-1}$ to obtain a first fraction called IEC-F1. Subsequently, a gradient was performed during $5 \mathrm{~h}$ starting with water and finishing with $2 \mathrm{M} \mathrm{NaCl}$ (flow rate: $20 \mathrm{~mL} \mathrm{~min}^{-1}$ ). A second fraction termed IECF2 was then obtained, eluting with $2 \mathrm{M} \mathrm{NaCl}$ (around $20 \mathrm{~L}$ ), at a flow rate of $20 \mathrm{~mL} \mathrm{~min}^{-1}$. The volume employed during the gradient phase was added to the $20 \mathrm{~L}$ corresponding to the fraction IEC-F2. The two fractions obtained were separately heated $\left(50^{\circ} \mathrm{C}\right)$ and concentrated using a cross flow filtration system (ÄKTA flux, GE Healthcare) (flow: $4 \mathrm{~L} \mathrm{~min}^{-1}$; TMP -corresponding to feed pressure - Retentate pressure-: 15 psi; column: UFP-30-C-4x2MA, $30 \mathrm{~kg} \mathrm{~mol}^{-1}$ ). Fractions IEC-F1 and IEC-F2 were afterward diafiltered against 10 volume of water in the same conditions to eliminate salts. The fractions were spray-dried using a B-290 Mini Spray Dryer $\left(\mathrm{BUCHI}^{\mathrm{TM}}\right)$.

\subsection{Yariv detection}

$\beta$-glucosyl Yariv reagent ( $\beta$-D-Glc Yariv reagent) has been largely used in the study of AGP (Osman et al., 1993; Paulsen, Craik, Dunstan, Stone, \& Bacic, 2014; Sims \& Furneaux, 2003). Petri dishes containing $1 \%$ agarose gel in $10 \mathrm{mM}$ Tris buffer, $\mathrm{pH} 7.3$, with $0.9 \% \mathrm{NaCl}$ and $1 \mathrm{mM}$ $\mathrm{CaCl}_{2}$ were used. $\beta$-D-Glucosyl Yariv reagent (Biosupplies, Victoria, Australia; $40 \mu \mathrm{L}, 1 \mathrm{mg} \mathrm{mL}^{-1}$ ) was delivered to a central well. Fractions IEC-F1 and IEC-F2 were placed in equidistant peripheral wells and petri dishes were left overnight at $25^{\circ} \mathrm{C}$. Arabinogalactan from larch wood (Sigma Aldrich, St. Louis, Mo) was used as negative control.

\subsection{Sugar composition as trimethylsilyl derivatives}

According to Doco, O'Neill, and Pellerin (2001), the neutral and acidic sugar composition was determined after solvolysis with anhydrous $\mathrm{MeOH}$ containing $0.5 \mathrm{M} \mathrm{HCl}\left(80{ }^{\circ} \mathrm{C}, 16 \mathrm{~h}\right)$ of their per-O-trimethylsilylated methyl glycoside derivatives, by gas chromatography (GC) on a Shimadzu GCMS-QP2010SE gas chromatograph (Shimadzu, Kyoto, Japan) connected to a flame ionization detector at $250^{\circ} \mathrm{C}$, using a fused silica DB-1 capillary column $(30 \mathrm{~m} \times 0.25 \mathrm{~mm}$ i.d., $0.25 \mu \mathrm{m}$ film) (temperature programming $120-200{ }^{\circ} \mathrm{C}$ at $1.5^{\circ} \mathrm{C} / \mathrm{min}$ ), with hydrogen as the carrier gas. The separation of the TMS derivatives was previously described (Apolinar-Valiente et al., 2014). 


\subsection{Amino acid analysis}

Total amino acids were analysed with a Biochrom 30 analyser (BIOCHROM 30, Cambridge, UK). Amino acid composition of samples was determined after acid hydrolysis $(6 \mathrm{~N} \mathrm{HCl})$ and heating at $110{ }^{\circ} \mathrm{C}$ for $24 \mathrm{~h}$. The excess of acid was eliminated and hydrolysed samples were analysed by liquid chromatography on an ion-exchange column (Ultra-pac-8 lithium form; Amersham Pharmacia Biotech, Piscataway). Lithium citrate $(0.2 \mathrm{M}, \mathrm{pH} 2.2)$ was used as eluent and norleucine as internal standard.

\subsection{Molar mass distribution analysis, static and dynamic molecular parameters}

Asen, fraction IEC-F1 and fraction IEC-F2 were analysed by size exclusion chromatography (SEC). The SEC line was constituted, depending on the analysis, by an OHPAK SB-G guard pre-column followed by one column (OHPAK SB 805 HQ, Shodex) for fraction IEC-F1, and four columns (OHPAK SB 803, 804, 805 and 806 HQ, Shodex) for fraction IEC-F2 and Asen. Selection of the appropriate type of columns for each sample was done after several testing (data not shown). The flow carrier $\left(0.1 \mathrm{M} \mathrm{LiNO}_{3}\right)$ was filtered $(0.1 \mu \mathrm{m}$ filter, Millipore) and pumped at $1 \mathrm{~mL} \mathrm{~min}^{-1}$. The samples were dissolved in filtered Milli-Q water $\left(1 \mathrm{mg} \mathrm{mL}^{-1}\right)$, stirred gently $(24 \mathrm{~h})$, centrifuged $(10000 \mathrm{rpm}$, $10 \mathrm{~min})$ and injected (10 $\mu \mathrm{L}$ for fraction IEC-F1 and $75 \mu \mathrm{L}$ for fraction IEC-F2 and Asen). Weight average $\left(\mathrm{M}_{\mathrm{w}}\right)$ and number average $\left(\mathrm{M}_{\mathrm{n}}\right)$ molar masses were determined using a multi-angle laser light scattering (MALLS) (DAWN-Heleos II from Wyatt, CA, USA), an on-line differential viscometer (VISCOSTAR II, Wyatt, CA, USA), a UV-VIS detector $(280 \mathrm{~nm})($ SPD-20A, Shimadzu, Japan) and a differential refractometer (Optilab T-Rex, Wyatt, Santa Barbara, CA, USA). The refractive index increment values $(d n / d c)$ were determined as $0.155,0.158$ and $0.155 \mathrm{~mL} \mathrm{~g}^{-1}$ for Asen, IEC-F1 and IEC-F2, respectively. The collected data were analysed using the Astra 6.1.84 software package.

\subsection{Density and sound velocity}

Density and sound velocity were determined using a DSA 5000M sonodensimeter (Anton Paar, France). Dispersions were prepared and dialyzed overnight against $0.1 \mathrm{M}$ sodium acetate buffer ( $\mathrm{pH}$ 5). Measurements were performed in degassed dispersions ( $15 \mathrm{~min})$ to remove dissolved air and triplicated.

\subsection{Dynamic light scattering (DLS)}

The translational diffusion coefficient $\left(\mathrm{D}_{\mathrm{T}}\right)$ was determined using a NICOMP nano Z (Z3000) equipment (PSS, USA). Dispersions were prepared at $5 \mathrm{~g} \mathrm{~L}^{-1}$ in deionized water $\left(18 \mathrm{~m} \Omega, \mathrm{pH} 5,25^{\circ} \mathrm{C}\right)$ and filtrated $(0.22 \mu \mathrm{m}$, VWR International, USA) to eliminate large aggregates. Measurements were performed at $25^{\circ} \mathrm{C}$ and in triplicate. Data were analysed using the NICOMP 2.0 software. The hydrodynamic radius $\left(R_{H}\right)$ was obtained from the autocorrelation curve, which was fitted using the cumulant method. In addition, the NICOMP software allowed the qualitative discrimination of up to three molecule populations using the non-linear least squares method.

\section{Results and discussion}

The objective of this work is to fractionate Asen gum through a separation method enabling to recover one single protein-rich fraction with high aggregate content. First, we will present the sugars and amino acid composition of the starting Asen, as well as its structural characteristics analyses. Secondly, we will show the yield of the aggregates recuperation and Yariv reagent precipitation after our fractionation of Asen by IEC. Finally, the sugars and amino acid composition, the structural analysis and some characteristics such as the number of
Table 1

Neutral sugars and uronic acids composition (\% molaire), characteristic ratios of Acacia senegal gum (Asen) and fractions HIC-F2, HIC-F3, IEC-F1T, IEC-F1 and IEC-F2.

\begin{tabular}{lllllll}
\hline & Asen & $\begin{array}{l}\text { Fraction } \\
\text { HIC-F2 }^{\mathrm{a}}\end{array}$ & $\begin{array}{l}\text { Fraction } \\
\text { HIC-F3 }^{\mathrm{a}}\end{array}$ & $\begin{array}{l}\text { Fraction } \\
\text { IEC-F1T }^{\mathrm{b}}\end{array}$ & $\begin{array}{l}\text { Fraction } \\
\text { IEC-F1 }\end{array}$ & $\begin{array}{l}\text { Fraction } \\
\text { IEC-F2 }\end{array}$ \\
\hline Arabinose & 29.8 & 35.6 & 38.3 & 37.5 & 35.5 & 26.0 \\
Rhamnose & 12.8 & 13.7 & 13.9 & 13.8 & 12.8 & 12.4 \\
Galactose & 38.5 & 34.4 & 33.3 & 33.6 & 33.5 & 40.5 \\
$\begin{array}{l}\text { Glucuronic Acid } \\
\text { 4-O-methyl }\end{array}$ & 17.9 & 15.6 & 13.7 & 14.3 & 17.3 & 19.8 \\
$\quad 1.0$ & 0.6 & 0.7 & 0.7 & 1.0 & 1.2 \\
$\quad \begin{array}{l}\text { Glucuronic } \\
\text { acid }\end{array}$ & & & & & & \\
$\begin{array}{c}\text { Ratio } \\
\quad \text { Arabinose/ }\end{array}$ & 0.8 & 1.0 & 1.2 & 1.1 & 1.1 & 0.7 \\
$\quad$ Galactose & & & & & & \\
\hline
\end{tabular}

a From Mejia Tamayo et al. (2018).

b Calculated considering that IEC-F1 is composed by $70 \%$ of HIC-F3 and $30 \%$ of $\mathrm{HIC}-\mathrm{F} 2$.

charges, the hydrophobicity index and the hydrodynamic radius of the obtained fractions will be presented, focusing mainly on the high aggregate-content fraction.

\subsection{The starting Asen}

To present our starting Asen properly, we show at first, its sugar composition (Table 1) and its total content of amino acids (Table 2). Subsequently, we give as determined by MALLS, differential refractometer and viscometer, the HPSEC-MALLS chromatogram (Fig. 1), as well as the data about molar mass distribution and static $\left(M_{w}, M_{n}\right.$ and $\mathrm{R}_{\mathrm{g}}$ ) and dynamic $([\eta])$ molecular parameters of Asen (Table 3).

\subsubsection{Sugars and amino acid composition of Asen}

The most abundant sugar components are galactose $(38.5 \%)$ and

Table 2

Amino acid composition (\%) and total amino acid content (mg amino acid. ${ }^{-1}$ of sample) of Acacia senegal gum (Asen), as well as fractions HIC-F2, HIC-F3, IEC-F1T, IEC-F1 and IEC-F2.

\begin{tabular}{|c|c|c|c|c|c|c|}
\hline Amino Acid & Asen & $\begin{array}{l}\text { Fraction } \\
\text { HIC-F2 }\end{array}$ & $\begin{array}{l}\text { Fraction } \\
\text { HIC-F3 }\end{array}$ & $\begin{array}{l}\text { Fraction } \\
\text { IEC-F1T }^{b}\end{array}$ & $\begin{array}{l}\text { Fraction } \\
\text { IEC-F1 }\end{array}$ & $\begin{array}{l}\text { Fraction } \\
\text { IEC-F2 }\end{array}$ \\
\hline Alanine & 2.1 & 1.7 & 2.7 & 2.4 & 2.2 & 1.9 \\
\hline Arginine & 1.7 & 1.0 & 2.2 & 1.9 & 2.1 & 1.3 \\
\hline Aspartic acid ${ }^{c}$ & 6.2 & 5.0 & 8.0 & 7.1 & 6.4 & 5.5 \\
\hline Glutamic Acid ${ }^{c}$ & 5.4 & 4.7 & 5.6 & 5.3 & 4.3 & 5.5 \\
\hline Glycine & 3.6 & 3.3 & 3.8 & 3.6 & 3.7 & 3.5 \\
\hline Hydroxyproline & 24.7 & 29.0 & 19.4 & 22.3 & 22.0 & 27.2 \\
\hline Histidine & 6.0 & 6.7 & 6.3 & 6.4 & 7.9 & 6.4 \\
\hline Isoleucine & 1.6 & 1.1 & 2.2 & 1.9 & 1.8 & 1.2 \\
\hline Leucine & 9.1 & 9.1 & 9.3 & 9.3 & 8.8 & 8.8 \\
\hline Lysine & 3.4 & 2.3 & 4.6 & 3.9 & 5.0 & 2.4 \\
\hline Phenylalanine & 4.6 & 4.7 & 5.6 & 5.3 & 4.1 & 4.4 \\
\hline Proline & 7.3 & 7.4 & 7.0 & 7.1 & 6.7 & 7.2 \\
\hline Serine & 11.3 & 12.4 & 10.3 & 10.9 & 11.9 & 12.0 \\
\hline Threonine & 6.9 & 7.5 & 6.2 & 6.6 & 6.9 & 7.2 \\
\hline Tyrosine & 1.3 & 0.6 & 1.5 & 1.2 & 1.9 & 0.7 \\
\hline Valine & 4.3 & 3.5 & 5.3 & 4.8 & 4.0 & 3.8 \\
\hline $\begin{array}{l}\text { Total (mg } \\
\text { amino } \\
\text { acid.g }{ }^{-1} \text { of } \\
\text { sample) }\end{array}$ & 19.6 & 46.2 & 118.0 & 96.5 & 114.9 & 15.9 \\
\hline
\end{tabular}

a From Mejia Tamayo et al. (2018), in Supplementary material.

b Calculated considering that IEC-F1 is composed by $70 \%$ of HIC-F3 and $30 \%$ of HIC-F2.

c The acid hydrolysis used in amino acid composition analysis converts asparagine to aspartic acid and glutamine to glutamic acid, or destroys some amino acids such as tryptophan, so these residues are not measured and not reported in the table. 
Time (min) for fraction IEC-F1(-)

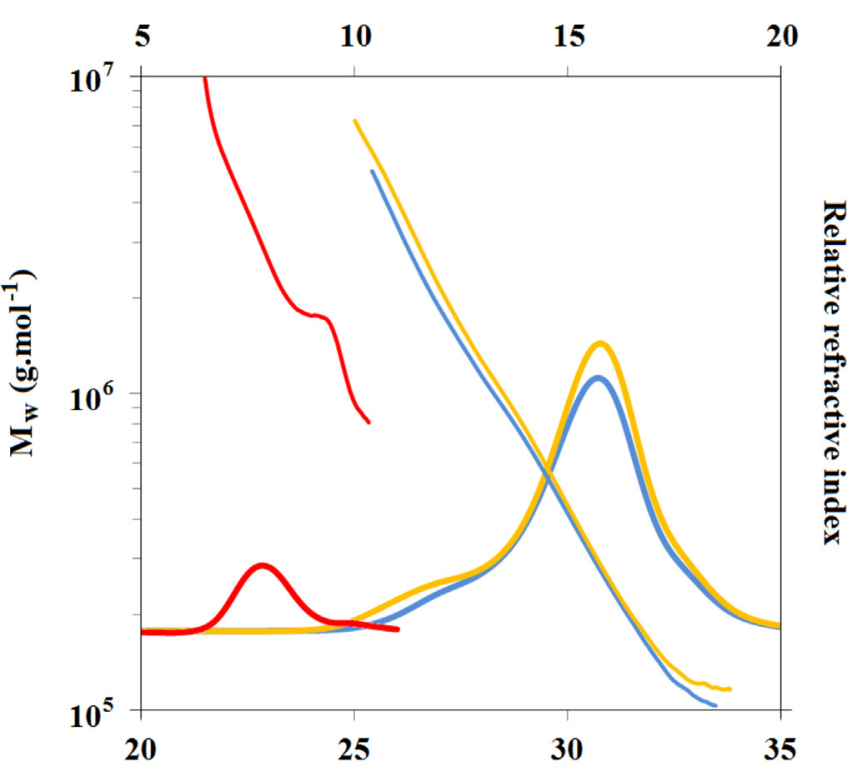

Time (min) for Asen $(-)$ and fraction IEC-F2 $(-)$

Fig. 1. Size exclusion chromatograms showing the elution profiles monitored by refractometer: relative refractive index (thick line) and molar mass ( $\mathrm{g} \cdot \mathrm{mol}^{-1}$; thin line) of Acacia senegal gum (Asen, egi10HHMDRSVOP) as well as of fractions IEC-F1 (egi10F1PN563G0) and IEC-F2 (egi10M13FFB2KT).

arabinose (29.8\%) (Table 1) being in agreement with its AGP nature. The calculated Ara/Gal molar ratio for Asen is 0.8. Likewise, our starting gum presents values of $12.8 \%$ for rhamnose, $1.0 \%$ for $4-O$ methyl glucuronic acid and $17.9 \%$ for glucuronic acid. All these values are consistent with those found in literature (Gashua et al., 2016; Idris et al., 1998; Lopez-Torrez et al., 2015; Nie et al., 2013; Renard et al., 2006).

As well, regarding the amino acid composition (Table 2), hydroxyproline is the most abundant amino acid found in Asen, serine being the second largest amino acid (Gashua, Williams, Yadav, \& Baldwin, 2015; Lopez-Torrez et al., 2015; Mahendran et al., 2008; Renard et al., 2006). This is in accordance with the inclusion of AGP in the group of the HRGPs (hydroxyproline-rich glycoproteins), which is a generic term covering all molecules that are rich in hydroxyproline/proline (generally $\geq 5 \%$ ) (Sommer-Knudsen, Bacic, \& Clarke, 1998). Other amino acids which present high percentages are leucine, proline and threonine, whereas alanine, arginine, isoleucine and tyrosine appear as minor amino acids. Focusing on the total content of amino acids, Asen shows $20 \mathrm{mg} \mathrm{g}^{-1}$ of sample, this is in agreement with values observed in gum samples by many authors (Osman et al., 1993; Randall et al., 1989).

3.1.2. Size exclusion chromatograms and $M_{w}$ distribution analysis, static and dynamic molecular parameters of Asen

The Asen chromatogram obtained by refractometry presents two macromolecular populations with different proportions (Fig. 1). The main population is eluted between 28 and $35 \mathrm{~min}$ (RI), being composed of low $\mathrm{M}_{\mathrm{w}}$ AGP. A second minor population also appears between 24 and $28 \mathrm{~min}$, corresponding to high $\mathrm{M}_{\mathrm{w}}$ AGP. Several authors have obtained similar profiles (Renard et al., 2006; Gashua et al., 2015; LopezTorrez et al., 2015) attributing the main peak to HIC-F1 along with a certain amount of HIC-F2, whereas the smallest peak mainly consists of most HIC-F2 as well as HIC-F3 and corresponds to aggregate population (Randall et al., 1989; Renard et al., 2006). Fig. 1 also presents the $\mathrm{M}_{\mathrm{w}}$ distribution (MWD) of Asen, being similar to this given in previous studies (Gashua et al., 2015; Lopez-Torrez et al., 2015; Renard et al., 2006).

Concerning the distribution analysis of Asen (Table 3), three different ranges have been selected in order to ensure a good comparison of the percentages of macromolecules with low (range 1: between $1 \times 10^{3}$ and $5 \times 10^{5} \mathrm{~g} \mathrm{~mol}^{-1}$ ), intermediate (range 2: between $5 \times 10^{5}$ and $1 \times 10^{6} \mathrm{~g} \mathrm{~mol}^{-1}$ ) and high (range 3 : between $1 \times 10^{6}$ and $1 \times 10^{7} \mathrm{~g} \mathrm{~mol}^{-1}$ ) molar masses. Asen shows statistically higher values in the range $1(67.5 \%)$ as compared to range $2(17.0 \%)$ and range 3 (15.4\%). The $\mathrm{M}_{\mathrm{w}}$ and $\mathrm{M}_{n}$ values for Asen are respectively $6.5 \times 10^{5} \mathrm{~g} \mathrm{~mol}^{-1}$ and $3.0 \times 10^{5} \mathrm{~g} \mathrm{~mol}^{-1}$, which is comparable with literature data (Gashua et al., 2015; Idris et al., 1998; Lopez-Torrez et al., 2015). In addition to molar masses, the radius of gyration $\left(\mathrm{R}_{\mathrm{g}}\right)$ is a useful parameter to characterize the polymer structure. This measure of molecular size was only taken into account for values above $10 \mathrm{~nm}$ due to the sensitivity limit of the MALLS detector. Using this criterion, $63 \%$ of macromolecules were considered, implying that this parameter must be carefully interpreted. The obtained value for Acacia gum $(29 \mathrm{~nm})$ is in agreement with that observed by Lopez-Torrez et al. (2015). However Sanchez, Renard, Robert, Schmitt, and Lefebvre (2002) and Gashua et al. (2015) found lower values for this parameter, which may be related to varying percentages of macromolecules considered to calculate this parameter. This fact could also be linked to the different origins of Acacia gum and/or the age of trees (Gashua et al., 2015; Idris et al., 1998). In this regard, the characterization of Acacia gum harvested on trees of different ages showed the gain in the proportion of aggregates in solution when the trees grow older up to about 15 years.

The intrinsic viscosity $([\eta])$ is directly linked to the hydrodynamic volume then related to the gum molar mass (Mudgil, Barak, \& Khatkar, 2012; Robinson, Ross-Murphy, \& Morris, 1982) and the hydration

Table 3

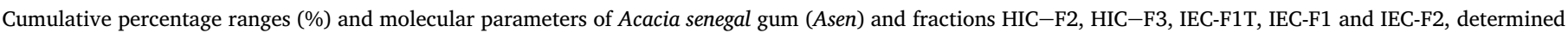
by SEC-MALLS, differential refractometer and viscometer.

\begin{tabular}{|c|c|c|c|c|c|c|}
\hline Ranges and Molecular parameters & Asen & Fraction HIC-F2 & Fraction HIC-F3 & Fraction IEC-F1T ${ }^{\mathrm{a}}$ & Fraction IEC-F1 & Fraction IEC-F2 \\
\hline Range $1\left(1 \times 10^{3}-5 \times 10^{5} \mathrm{~g} \mathrm{~mol}^{-1}\right)$ & 67.5 & $4.4^{\mathrm{d}}$ & $17.6^{\mathrm{d}}$ & 13.6 & 0.0 & 70.3 \\
\hline Range $2\left(5 \times 10^{5}-1 \times 10^{6} \mathrm{~g} \mathrm{~mol}^{-1}\right)$ & 17.0 & $22.9^{\mathrm{d}}$ & $26.9^{\mathrm{d}}$ & 25.7 & 2.6 & 18.2 \\
\hline Range $3\left(1 \times 10^{6}-1 \times 10^{7} \mathrm{~g} \mathrm{~mol}^{-1}\right)$ & 15.4 & $72.7^{\mathrm{d}}$ & $55.6^{\mathrm{d}}$ & 60.7 & 97.4 & 11.5 \\
\hline $\mathrm{M}_{\mathrm{w}}\left(\mathrm{g} \cdot \mathrm{mol}^{-1}\right)$ & $6.5 \times 10^{5}$ & $1.5 \times 10^{6 \mathrm{~b}}$ & $1.6 \times 10^{6 \mathrm{~b}}$ & $1.6 \times 10^{6}$ & $3.1 \times 10^{6}$ & $5.3 \times 10^{5}$ \\
\hline$M_{n}\left(g \cdot \mathrm{mol}^{-1}\right)$ & $3.0 \times 10^{5}$ & $1.1 \times 10^{6 \mathrm{~b}}$ & $9.0 \times 10^{5 b}$ & $9.6 \times 10^{5}$ & $2.5 \times 10^{6}$ & $2.8 \times 10^{5}$ \\
\hline $\mathrm{R}_{\mathrm{g}}(\mathrm{nm})$ & 28.6 & $29.4^{\mathrm{d}}$ & $33.3^{\mathrm{d}}$ & $\mathrm{nc}^{\mathrm{c}}$ & 44.0 & 23.0 \\
\hline Polydispersity $\left(M_{w} / M_{n}\right)$ & 2.2 & $1.3^{\mathrm{b}}$ & $1.9^{\mathrm{b}}$ & 1.7 & 1.2 & 1.9 \\
\hline Intrinsic viscosity $\left(\mathrm{mL} \cdot \mathrm{g}^{-1}\right)$ & 30.2 & $64.3^{\mathrm{d}}$ & $54.7^{\mathrm{d}}$ & 57.6 & 87.8 & 29.2 \\
\hline
\end{tabular}

${ }^{\text {a }}$ Calculated considering that IEC-F1 is composed by $70 \%$ of HIC-F3 and 30\% of HIC-F2.

b Adapted from Mejia Tamayo et al. (2018).

c Nc: not calculated.

d Some of the data shown in Table 3 were not described in Material and Methods section. We used these data for purpose of comparison and simplification. 

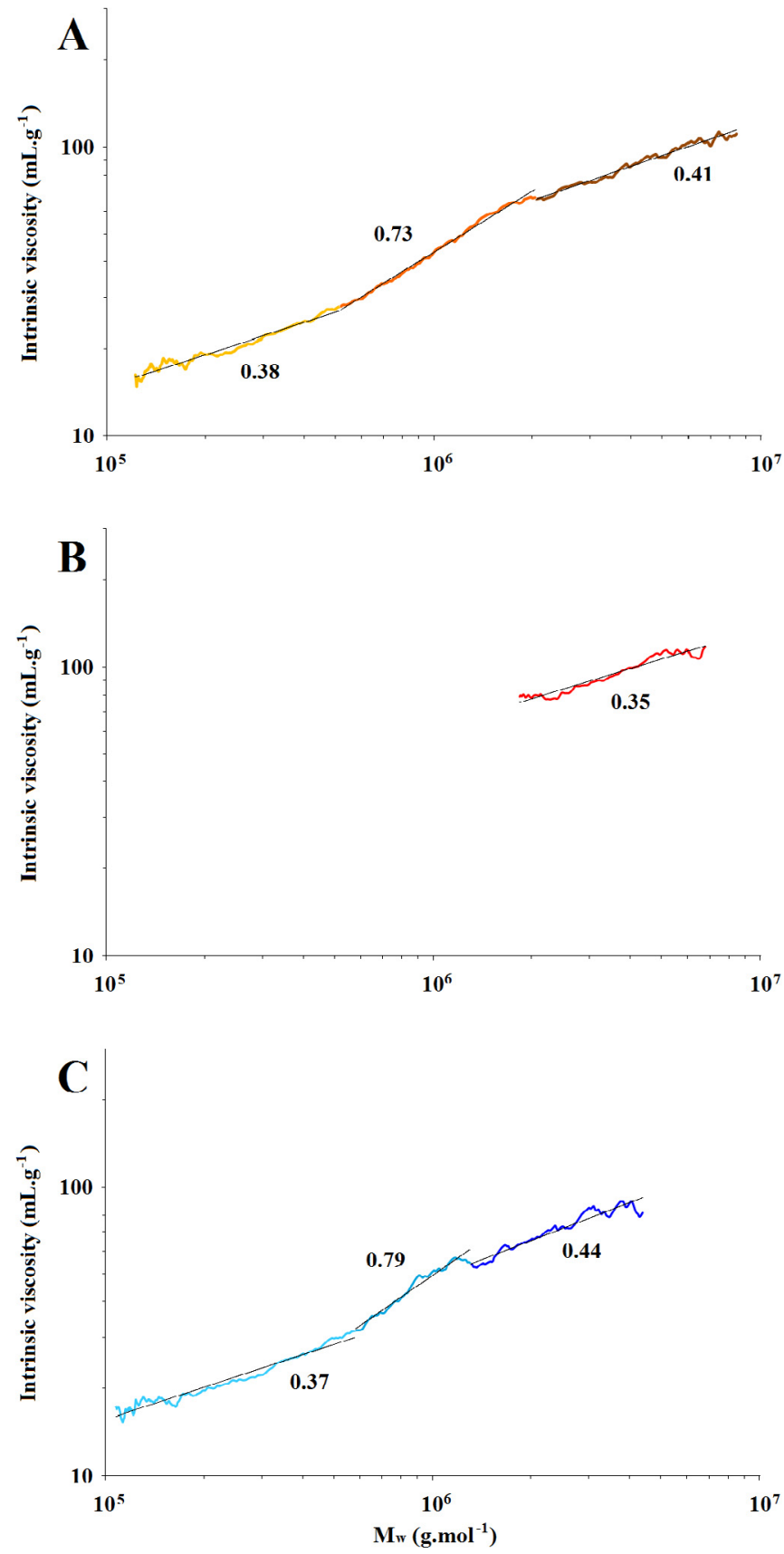

Fig. 2. Mark-Houwink-Sakurada (MHS) plot showing the intrinsic viscosity $\left([\eta] ; \mathrm{mL}^{-1}\right)$ as a function of molar mass $\left(\mathrm{M}_{\mathrm{w}} ; \mathrm{g} \cdot \mathrm{mol}^{-1}\right)$ for Asen (Fig. A) and fractions IEC-F1 (Fig. B) and IEC-F2 (Fig. C).

status and conformation of macromolecules. This in turn is linked to the primary sugars and amino acid composition and the structure of AGP (topological complexity, surface roughness, presence of grooves, etc.). The $[\eta]$ is widely used to study the structural properties of biopolymers and the effects of the solvent environment on the stability of polymers in solution (Sibaja-Hernández, Román-Guerrero, Sepúlveda-Jiménez, \& Rodríguez-Monroy, 2015). The $[\eta]$ value for Asen is $30 \mathrm{~mL} \mathrm{~g}^{-1}$, which is within the defined range (between 15 and $31 \mathrm{~mL} \mathrm{~g}^{-1}$ ) reported in literature (Bai et al., 2017; Karamalla, Siddig, \& Osman, 1998; LopezTorrez et al., 2015; Sanchez et al., 2002; Vandevelde \& Fenyo, 1985). These low values are a known characteristic of hyperbranched polymers (Aerts, 1998; Yan, Gao, \& Frey, 2011).

Fig. 2 shows the Mark-Houwink-Sakurada (MHS) analysis, relating the intrinsic viscosity $[\eta]$ to $\mathrm{M}_{\mathrm{w}}$. The relation between these two

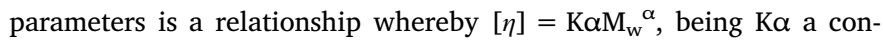
stant and $\alpha$ exponent value is called hydrodynamic coefficient (Burchard, 1999). The hydrodynamic coefficient is presented by plot slopes, providing deeper information about conformation and structure of macromolecules. This hydrodynamic coefficient theoretically varies from 0 (sphere) to 1.8 (rod) with values of $0.3-0.5$ for hyperbranched polysaccharides (Callaghan \& Lelievre, 1985; Lelievre, Lewis, \& Marsden, 1986; Millard, Dintzis, Willett, \& Klavons, 1997; RollandSabaté, Mendez-Montealvo, Colonna, \& Planchot, 2008) and values of $0.5-0.8$ for flexible polymers depending on the solvent quality (RossMurphy, 1994). It can be observed that MHS plot from Asen cannot be described by one slope but by three, which is in total accordance with data reported by Lopez-Torrez et al. (2015). The $\alpha$ values are lower than 0.5 for the first part (low $\mathrm{M}_{\mathrm{w}}$ ranges) and the last part (high $\mathrm{M}_{\mathrm{w}}$ ranges) of Asen. According to the above mentioned works, all of them correspond to hyperbranched structures. In the same vein, $\mathrm{Li}, \mathrm{Lu}, \mathrm{An}$, and $\mathrm{Wu}$ (2013) reported similar results with synthetic hyperbranched polymers. Besides, the molecules with $\alpha$ values between 0.3 and 0.4 would theoretically correspond to spheroid structure (Burchard, 1999). On the other hand, $\alpha$ exponents for intermediate parts of Asen show values between 0.6 and 0.7 , which are suggested as linear random coil conformation. However, these high $\alpha$ values seems to disagree with the largely proved fact that Acacia gum macromolecules are hyperbranched polymers. It is important to highlight that the molecular polydispersity and the effect of chain branching requires a careful interpretation for polymers having complex hydrodynamics (Ross-Murphy, 1994). Anisotropy, temperature, polymer-solvent interactions and polydispersity influence $\alpha$ exponent values. Moreover, Lopez-Torrez et al. (2015) found similar trends studying Asen gum, suggesting that the intermediate range of $\mathrm{M}_{\mathrm{w}}$ might imply larger anisotropy or smaller chain density than the other two ranges (low and high $\mathrm{M}_{\mathrm{w}}$ range). Concerning the average values, $\alpha$ exponent value of Asen (0.52) is similar to those previously obtained, which ranged between 0.51 and 0.55 (listed by Lopez-Torrez et al., 2015).

\subsection{Fractionation of Asen by IEC: yield of the aggregates recuperation and} Yariv reagent precipitation

In the light of all the data shown in previous sections, we can confirm that our starting Asen gum corresponds to a conventional and largely referenced Asen gum. Therefore, our gum is a good starting point to achieve our prime objective, that is to say, to obtain a fraction with high content of aggregates from Asen. Consequently, we have completed the IEC fractionation. $581 \mathrm{~g}$ (dry matter) of Asen were loaded on IEC column. After all the steps of fractionation, $25 \mathrm{~g}$ ( $4.3 \%$ of initial gum) of fraction IEC-F1 and $496 \mathrm{~g}$ (85.4\% of initial gum) of fraction IEC-F2 were recovered. In our opinion, the total yield ( $89.7 \%$ of initial gum) can be considered as satisfactory, because losses can occur during the fractionation, concentration step, diafiltration and spray-drying procedures. The total recovery yield of aggregates might be optimized, but this is not our primary objective.

Yariv's reagent precipitates both fractions IEC-F1 and IEC-F2 (Fig. 3). This fact corroborates as expected that they belong to AGP family. In the same line of our results, two fractions from gum separated by preparative GPC (Qi, Fong, \& Lamport, 1991) were found to interact with Yariv reagent, as well as four fractions separated by HIC (Osman et al., 1993).

\subsection{Fractions IEC-F1 and IEC-F2: composition and structure}

Given that our objective is a fraction with high content of aggregates, we will mainly focus our discussion on the results of the fraction IEC-F1. The data obtained from IEC-F2 are also shown in the different Tables and Figures, being similar to those from Asen. 


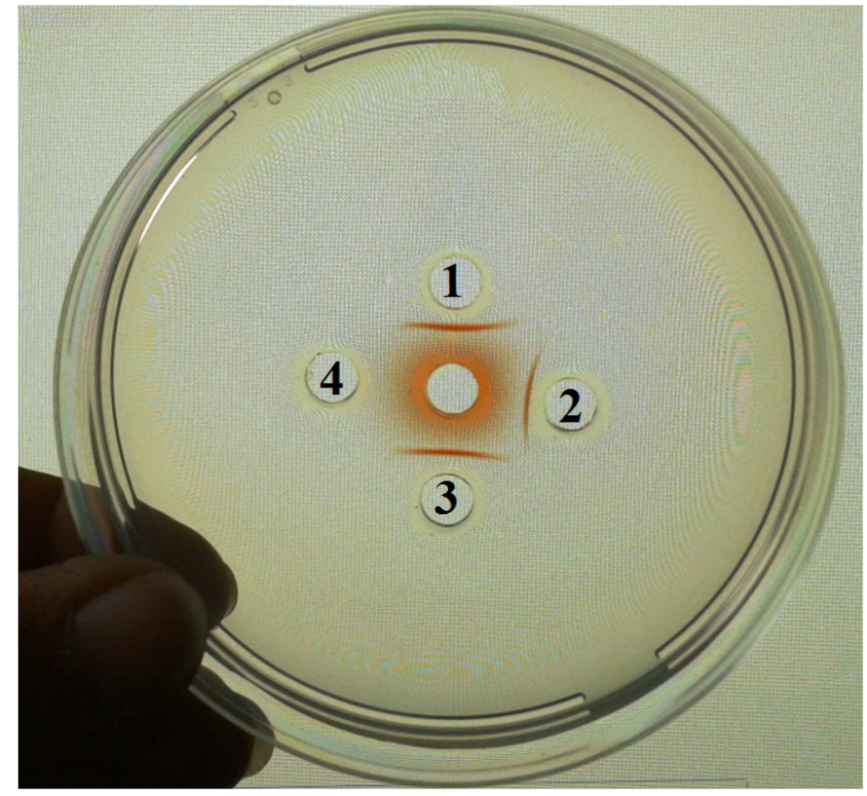

Fig. 3. Yariv's reagent analysis for fraction IEC-F1 (1), fraction IEC-F2 (2), Asen (3) and AGP from larch wood (4).

\subsubsection{Sugars and amino acid composition of fractions IEC-F1 and IEC-F2}

Table 1 shows the neutral sugars and uronic acid composition of the IEC-F1 fraction. As above mentioned, arabinose and galactose appears as major component. Fraction IEC-F1 shows high molar percentage of arabinose (36\%) and low percentage of galactose (34\%). These results are in the line of those previously obtained by Randall et al. (1989) and Renard et al. (2006). We find a smaller content of glucuronic acid groups in the case of fraction IEC-F1, which may induce lower electrostatic repulsions and, hence, a higher tendency to aggregation compared to the other two samples studied (Asen and fraction IEC-F2). It has been observed that, studying the emulsifying properties of Acacia gum, the polar heads contain a negative charge derived from the glucuronic acids, which creates a barrier of repulsive forces preventing oil droplets aggregation (Nieto, 2014). Ferreira, Freitas, and Teixeira (2003) found that certain carbohydrate, including glucuronic acid, interfered with the self-aggregation of legume seed storage proteins process. Randall et al. (1989) and Renard et al. (2006) also found lower uronic acids amount in HIC-F3 fraction in comparison to fraction HIC-F1 of the Acacia gum.

The amino acid composition and total amino acid content of fraction IEC-F1 are presented in Table 2. As expected, hydroxyproline appears as the largest amino acid contained in fraction IEC-F1, followed by serine. Other amino acids which present high percentages are leucine and histidine. If we focus on the total content of amino acids, fraction IEC-F1 presents a large value $\left(115 \mathrm{mg}\right.$ amino acid. ${ }^{-1}$ of sample). Several authors have reported different content of amino acid depending on the obtained fraction, whatever the procedure of separation employed (Osman et al., 1995; Qi et al., 1991; Randall et al., 1989). Differences of protein content and amino acids composition have been suggested as the cause of the varying aggregation behavior of classical HIC-obtained fractions. The high protein amount as well as the greater percentage of hydrophobic amino-acids in HIC-F3 fraction would hence justify the highest sensitivity of macromolecules from this fraction towards self-assembly and subsequent aggregation in aqueous solution (reviewed by Sanchez et al., 2018). From that, and keeping in mind its high total content of amino acids, it seems logical to conclude that our fraction IEC-F1 would show a high trend to form aggregates, corresponding to our objective.

From the amino acid composition and content, it can be easily deduced that, as expected, high aggregate-content IEC-F1 fraction is mainly composed by classical HIC-F2 and HIC-F3 fractions. We have roughly estimated, using the corresponding data reported in Supplementary material by Mejia Tamayo et al. (2018) on HIC-F2 and HIC-F3 fractions and testing different percentages, that IEC-F1 is formed by around $70 \%$ of fraction HIC-F3 and 30\% of fraction HIC-F2. Using these estimated percentages, we calculate the composition of a theoretical fraction named IEC-F1T, whose planned composition data are also shown in Tables 1 and 2. Regarding Table 2, we can observe that the amino acids composition and total content of experimental IEC-F1 fraction corresponds reasonably to our theoretical IECF1T fraction. Concerning Table 1, the neutral sugars and uronic acids composition of IEC-F1 fraction matches a little less with our calculated IEC-F1T fraction, although the mentioned corresponding tendency continues to be observed. Moreover, it should be noted that our experimental IEC-F1 fraction would also present a certain percentage of fraction HIC-F1, although it has been not taken into account with a view to simplify the theoretical calculations.

\subsubsection{Size exclusion chromatograms and $M_{w}$ distribution of fractions IEC-} F1 and IEC-F2

Regarding the chromatogram of fraction IEC-F1 (Fig. 1, one Shodex column used), the elution time from its major population (RI signal) corresponds to values between 5 and $9 \mathrm{~min}$, and presents high $\mathrm{M}_{\mathrm{w}}$. This population is classically identified as HIC-F2 and HIC-F3 fractions (Mejia Tamayo et al., 2018; Randall et al., 1989; Renard et al., 2006), the major components of IEC-F1 aggregates. A minor and hardly separable population can also be deduced as a shoulder between 9 and 11 min, showing low $\mathrm{M}_{\mathrm{w}}$. Concerning the MWD of fraction IEC-F1, the fact that we have used only one Shodex column to reduce anomalous diffusion effects of high $\mathrm{M}_{\mathrm{w}}$ hyperbranched molecules explains the different MWD slope. In any case, the MWD curve of fraction IEC-F1 is located above these of fraction IEC-F2 and Asen along almost all the elution time. Concerning molar mass distribution of IEC-F1 aggregates, it shows high value (97.4\%) in range 3, whereas no or low $(2.5 \%)$ molar mass appears in ranges 1 and 2 (Table 3). Looking at all these results, they are in coherence with the fact that, as expected, we get a part of the AGP with high $\mathrm{M}_{\mathrm{w}}$ from Asen with our IEC procedure, corresponding to fraction IEC-F1. Moreover, we have obtained a significant difference between the molar mass distribution of IEC-F1 aggregates and those calculated for IEC-F1T using the constituent assigned ratio [70\% of HIC-F3 and 30\% of HIC-F2] (Table 3): range 1: 13.6\%, range 2: $25.7 \%$ and range $3: 60.7 \%$. These great differences, particularly in the case of range 3 , can be attributed to the gain of aggregates.

From the whole data shown above, we can conclude that the charge plays the most important role in our IEC separation, although it can also be important to consider the accessibility of the charged molecules to the gel. In this regard, we think that the hydrodynamic volume of the macromolecules also plays a part in our separation. The possibility of a steric disability using anion-exchange chromatography to fractionate Acacia gum was previously reported by Osman et al. (1995).

\subsubsection{Static and dynamic molecular parameters of fractions IEC-F1 and IEC-F2}

Table 3 shows the static and dynamic parameters of fractions IEC-F1 and IEC-F2. From the data reported by Mejia Tamayo et al. (2018) we have also calculated the $\mathrm{M}_{\mathrm{w}}$ and $\mathrm{M}_{\mathrm{n}}$ values of our theoretical IEC-F1T fraction (Table 3), again using the constituent assigned ratio $[70 \%$ of HIC-F3 and $30 \%$ of HIC-F2]. Therefore, we have obtained an enormous difference between the calculated $\mathrm{M}_{\mathrm{w}}\left(1.6 \times 10^{6} \mathrm{~g} \mathrm{~mol}^{-1}\right)$ and $M_{n}\left(9.6 \times 10^{5} \mathrm{~g} \mathrm{~mol}^{-1}\right)$ values of IEC-F1T and the experimental data of IEC-F1 $\left(\mathrm{M}_{\mathrm{w}}: 3.1 \times 10^{6} \mathrm{~g} \mathrm{~mol}^{-1}\right.$ and $\left.\mathrm{M}_{\mathrm{n}}: 2.5 \times 10^{6} \mathrm{~g} \mathrm{~mol}^{-1}\right)$. These great differences between theoretical and experimental results can be explained by the presence of aggregates, whose high level would increase the $M_{w}$ and $M_{n}$ values. From these values, the polydispersity value $\left(\mathrm{M}_{\mathrm{w}} / \mathrm{M}_{\mathrm{n}}\right)$ of the fraction IEC-F1 shows logically lower value (1.2) compared with the fraction IEC-F1T (1.7). 
It must be remarked that, as previously mentioned, the radius of gyration $\left(\mathrm{R}_{\mathrm{g}}\right)$ of each sample was only taken into account for values above $10 \mathrm{~nm}$. Using this criterion, $100 \%$ of macromolecules from fraction IEC-F1 are considered, resulting in a very high $R_{g}$ value (44 nm). This result is logical knowing that, as calculated, fraction IECF1 is formed by $70 \%$ of HIC-F3 and that Renard et al. (2006) reported that HIC-F3 fraction showed higher $R_{g}$ values compared to predominant HIC-F1 fraction. We have not calculated the $\mathrm{R}_{\mathrm{g}}$ values of IEC-F1T fraction because of the difficulties involved in used percentage of macromolecules used to this calculation. However, it can be valuable to note that we previously found $\mathrm{R}_{\mathrm{g}}$ values of $29.4 \mathrm{~nm}$ and $33.3 \mathrm{~nm}$ in, respectively, fraction HIC-F2 and HIC-F3 (Table 3). Therefore, even without estimating the precise $R_{g}$ value of IEC-F1T, we can deduce an obvious difference between theoretical and experimental values for this parameter. Al-Assaf et al. (2009) observed that an increase of $R_{g}$ from 33 to $73 \mathrm{~nm}$ was caused by aggregation involving hydrophobic association of the proteinaceous components from Acacia gum molecules after heating treatment. The same authors reported an increase of $\mathrm{R}_{\mathrm{g}}$ from 25 to $67 \mathrm{~nm}$ after irradiation treatment of Acacia gum, explaining this aggregation through $\mathrm{C}-\mathrm{C}$ covalent bonds between the carbohydrate moieties. Therefore, high values of $R_{g}$ parameters could be also linked to aggregation phenomenon.

The intrinsic viscosity ( $[\eta]$ ) (Table 3 ) of high aggregate-content IECF1 fraction appears as a very high $\left(87.8 \mathrm{~mL} \mathrm{~g}^{-1}\right)$ value. This parameter in Acacia gum has been suggested as strongly linked to the protein content (Chikamai, Banks, Anderson, \& Weiping, 1996) as well as to the molar mass. Al-Assaf et al. (2007) associated a rise of 20 -fold in fluid viscosity with an increase of molar mass from $4.24 \times 10^{5}$ to $14.5 \times 10^{5} \mathrm{~g} \mathrm{~mol}^{-1}$ during a maturation procedure of Asen gums. The $[\eta]$ value (Table 3 ) and the amino acid total content (Table 2 ) of fraction IEC-F1 are in perfect coherence with these two remarks, which can be explained by the fact that protein-rich macromolecules in Acacia gum display generally high $\mathrm{M}_{\mathrm{w}}$. Moreover, we have calculated the $[\eta]$ value of IEC-F1T fraction $\left(57.6 \mathrm{~mL} \mathrm{~g}^{-1}\right)$ through the constituent assigned ratio $[70 \%$ of $\mathrm{HIC}-\mathrm{F} 3$ and $30 \%$ of HIC-F2], knowing that HIC-F2 and HIC-F3 presents values of 64.3 and $54.7 \mathrm{~mL} \mathrm{~g}^{-1}$ (Table 3). The great difference of $[\eta]$ values between fraction IEC-F1 and fraction IEC-F1T might be attributed to the aggregates. In this line, Li et al. (2009) reported that the viscosity reduces synchronously with dissociation of aggregates.

The results of Mark-Houwink-Sakurada (MHS) analysis for fractions IEC-F1 and IEC-F2 are shown in Fig. 2. MHS plot from fraction IEC-F1 can be described by one single slope. The $\alpha$ value is lower than 0.5 for fraction IEC-F1, which would correspond to hyperbranched structures. $\mathrm{Li}$ et al. (2013) reported the same conclusions using synthetic hyperbranched polymers. As said before, the macromolecules showing $\alpha$ values between 0.3 and 0.4 would be theoretically identified as spheroid structures (Burchard, 1999). Renard, Lavenant-Gourgeon, Lapp, Nigen, and Sanchez (2014b) found that fraction HIC-F3 showed a hydrodynamic coefficient value of 0.45 , which is close to our value for fraction IEC-F1 (0.35), but even higher than the latter. The explanation of the observed lower $\alpha$ value of fraction IEC-I would correspond to the presence of aggregates, as shown by Bello-Pérez, Roger, Colonna, and Paredes-López (1998), which would perfectly conform to our principal aim.

As shown by Lopez-Torrez et al. (2015) in Asen, Fig. 4 compares theoretical calculations of objects with increasing anisotropy (spheres, oblate and prolate ellipsoids and rods) with our obtained results. Fraction IEC-F1 shows prolate ellipsoid conformation, whereas fraction IEC-F2 contains molecules with more oblate ellipsoid-like conformation at low $\mathrm{M}_{\mathrm{w}}$ and more anisotropic conformations at larger $\mathrm{M}_{\mathrm{w}}$. The aggregates in fraction IEC-F1 could hence influences on its conformation. In this vein, Callaghan, Lelievre, and Lewis (1987) found that wheat amylopectin dispersed in DMSO solutions corresponded to an oblate ellipsoid conformation, whereas the same molecules dispersed in water aggregated to yield a more spherical shape.

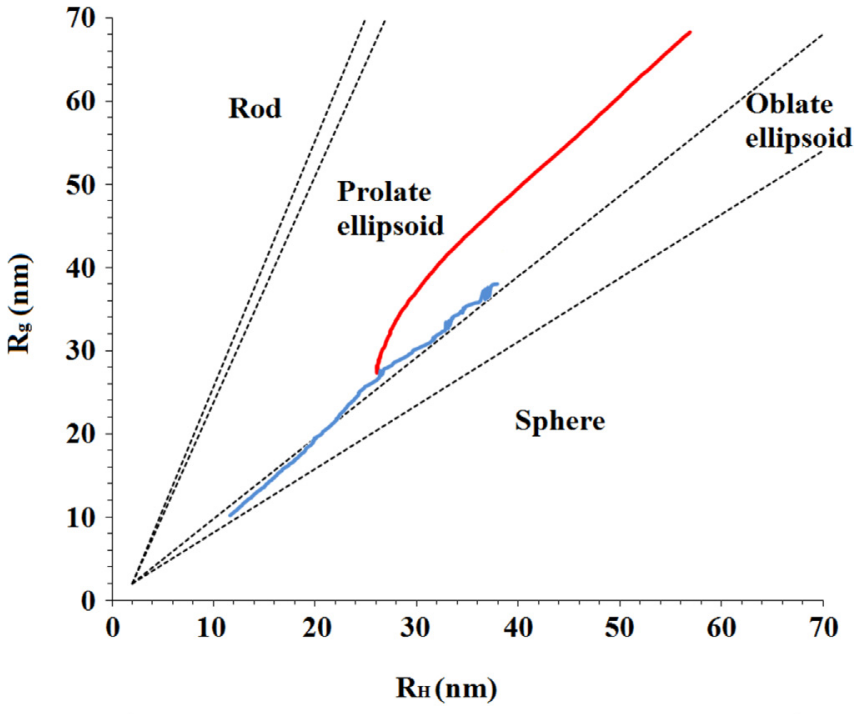

Fraction IEC-F1( - Fraction IEC-F2 $(-)$

Fig. 4. Radius of gyration $\left(R_{g}\right)$ as a function of hydrodynamic radius $\left(R_{H}\right)$ for fractions IEC-F1 (egi10F1PN563G0) and IEC-F2 (egi10M13FFB2KT). Black lines represent theoretical calculations for objects with increasing anisotropy (from Lopez-Torrez et al., 2015).

\subsubsection{Number of charges and hydrophobicity index of fractions IEC-F1 and IEC-F2}

The contribution of the polysaccharide and protein moiety of IEC fractions to basic molecular characteristics has been calculated by combining the biochemical and structural properties (Table 4). The average $\mathrm{M}_{\mathrm{w}}$ of the polysaccharide and protein part have been estimated considering the sugar (Table 1) and amino acid (Table 2) composition of each sample. The amount of free $\mathrm{OH}$ in the polysaccharide part was calculated through the linkage of the neutral sugars and the number of possible interacting sites of the protein portion, bearing in mind the interacting sites of each amino acid. Finally the hydrophobicity was

Table 4

Basic molecular characteristics of Acacia senegal gum (Asen), as well as fractions IEC-F1 and IEC-F2.

\begin{tabular}{|c|c|c|c|}
\hline & Asen & $\begin{array}{l}\text { Fraction } \\
\text { IEC-F1 }\end{array}$ & $\begin{array}{l}\text { Fraction IEC- } \\
\text { F2 }\end{array}$ \\
\hline $\mathrm{M}_{\mathrm{w}}\left(\mathrm{g} \cdot \mathrm{mol}^{-1}\right)$ & 645500 & 3100000 & 529900 \\
\hline Sugars $(\%)^{\mathrm{a}}$ & 94.71 & 88.21 & 92.56 \\
\hline Proteins (\%) & 1.96 & 11.49 & 1.59 \\
\hline Polysaccharide moiety $\mathrm{M}_{\mathrm{w}}\left(\mathrm{g} \cdot \mathrm{mol}^{-1}\right)$ & 632848 & 2743810 & 521475 \\
\hline Average sugar residue $\mathrm{M}_{\mathrm{w}}\left(\mathrm{g} \cdot \mathrm{mol}^{-1}\right)$ & 175.1 & 170.2 & 173.1 \\
\hline Number of sugar residues & 3613 & 16123 & 3012 \\
\hline Average total free $\mathrm{OH} /$ residue & 2.96 & 3.05 & 3.12 \\
\hline $\begin{array}{l}\text { Potential number of charged and polar } \\
\text { interacting sites (polysaccharide } \\
\text { moiety) }\end{array}$ & 10699 & 49210 & 9395 \\
\hline Protein moiety $\mathrm{M}_{\mathrm{w}}\left(\mathrm{g} \cdot \mathrm{mol}^{-1}\right)$ & 12652 & 356190 & 8425 \\
\hline $\begin{array}{l}\text { Average amino acid residue } M_{w} \\
\left(\mathrm{~g} \cdot \mathrm{mol}^{-1}\right)\end{array}$ & 128.1 & 129.3 & 128.0 \\
\hline Number of amino acid residues & 99 & 2755 & 66 \\
\hline Non-polar amino acids (\%) & 26.8 & 27.7 & 27.6 \\
\hline Number of interaction sites & 0.85 & 0.85 & 0.84 \\
\hline $\begin{array}{l}\text { Potential number of charged and polar } \\
\text { interacting sites (protein moiety) }\end{array}$ & 92 & 1915 & 63 \\
\hline $\begin{array}{l}\text { Potential number of non-polar } \\
\quad \text { interacting sites (protein moiety) }\end{array}$ & 16 & 329 & 12 \\
\hline Hydrophobicity index & -1.18 & -1.39 & -1.15 \\
\hline
\end{tabular}

a Sugars percentage was determined by the difference of proteins and minerals from $100 \%$ of sample. 
determined using the amino acid hydrophobicity scale proposed by Zhu et al. (2016).

From the number of polar and charged interacting sites of the polysaccharide portion, the number of charges contributed by fraction IEC-F1 is much higher than fraction IEC-F2 (49210 and 9395, respectively), which may be explained by their corresponding content of sugar residues (16123 and 3012, respectively) (Table 4). Regarding the protein part, the number of charges contributed by fraction IEC-F1 is also much higher (1915) than fraction IEC-F2 (63), being explained by their corresponding content of amino acid residues (2755 and 66, respectively) (Table 4).

Concerning the hydrophobicity index, fraction IEC-F1 appears as more hydrophobic $(-1.39)$ than fraction IEC-F2 $(-1.15)$, which seems coherent bearing in mind the number of non-polar interacting sites (329 and 12, respectively). Therefore, although our IEC fractionation methodology separates the macromolecular fractions mainly in terms of hydrodynamic volume and number of charge sites, the occurrence of hydrophobic interactions could also be suggested.

\subsubsection{Hydrodynamic radius of fractions IEC-F1 and IEC-F2}

The hydrodynamic radius $\left(\mathrm{R}_{\mathrm{H}}\right)$ of Asen and its fractions IEC-F1 and IEC-F2 was calculated from the translational diffusion coefficient $\left(D_{T}\right)$, which was obtained from the autocorrelation curves. The autocorrelation curves of Asen, IEC-F1 and IEC-F2 obtained from measures of a 5 g.L $\mathrm{L}^{-1}$ prepared in a salt-free dispersion are presented in Fig. 5. Small molecules tend to move faster than large molecules. Thus, they have a bigger impact on the fluctuation of the intensity signal. Therefore, its autocorrelation curve presents a faster decay. The results show a clear influence of the presence of supramolecular assemblies in the IEC-F1 fraction, since for the same decay time a higher intensity of the signal was measured. Therefore, our results are in accordance with the theory. In addition, the NICOMP analysis allowed the qualitative discrimination of up to three molecule populations. These results together with the

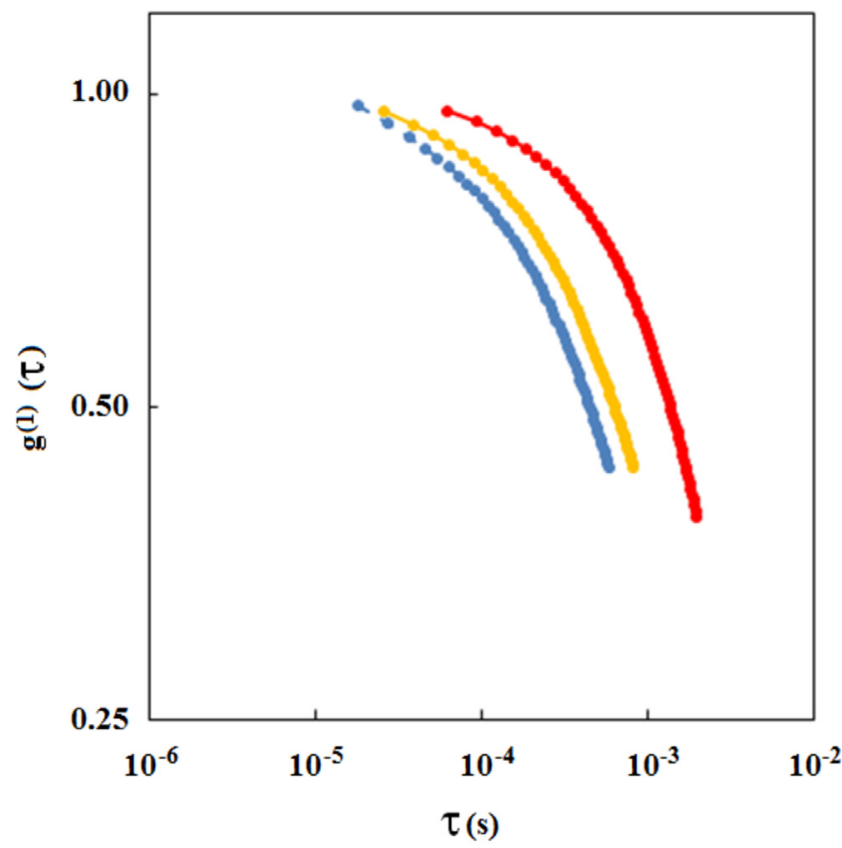

Asen $\left({ }_{-}\right)$Fraction IEC-F1 $(-)$Fraction IEC-F2 (

Fig. 5. Autocorrelation curves of: Acacia senegal gum (Asen, egi10HHMDRSV0P), IEC-F1 (egi10F1PN563G0) and IEC-F2 (egi10M13FFB2KT) fractions. Measurements were performed at $5 \mathrm{~g} \mathrm{~L}^{-1}$ in deionized water (pH 5) at $25^{\circ} \mathrm{C}$ using dynamic light scattering (DLS). $\mathrm{g}^{(1)}$ : the intensity of the signal (photon count, in vertical axe); $\tau$ : the decay time (s, in horizontal axe).
Table 5

Hydrodynamic radius (RH) $\left(\beta_{\mathrm{s}}{ }^{\circ}\right)$ of Acacia senegal gum (Asen), IEC-F1 and IECF2 obtained from dynamic light scattering (DLS). Measurements were done in $5 \mathrm{~g} \mathrm{~L}^{-1}$ prepared in deionized water.

\begin{tabular}{llll}
\hline & Asen & Fraction IEC-F1 & Fraction IEC-F2 \\
\hline $\mathrm{R}_{\mathrm{H}}{ }^{\mathrm{a}}$ (nm) & 50 & 70 & 35 \\
Populations (nm) & $6 ; 28 ; 150$ & $17 ; 75 ; 250$ & $6 ; 18 ; 49$ \\
\hline
\end{tabular}

${ }^{a} R_{H}$ was calculated from the autocorrelation curve (Fig. 5), assuming a Gaussian distribution of the molecules. Molecule populations were calculated using the NICOMP method.

hydrodynamic radius (z-average) are presented in Table 5 . The results show a clear influence of the presence of supramolecular assemblies in the IEC-F1 fraction, since for the same decay time a higher intensity of the signal was measured. As expected, the high aggregate-content IECF1 fraction displayed a higher $\mathrm{R}_{\mathrm{H}}(70 \mathrm{~nm})$ than Asen and IEC-F2 (50 and $35 \mathrm{~nm}$, respectively). Furthermore, IEC-F1 showed three molecule populations with a $R_{H}$ around 17, 75 and $250 \mathrm{~nm}$. Thus, the presence of large supramolecular assemblies in this fraction was confirmed. Presence of supramolecular assemblies of around 150 and $125 \mathrm{~nm}$ were also seen in experiments performed using HIC-F2 and HIC-F3, respectively (results not shown). Thus, further self-aggregation induced by the presence of HIC-F2 and HIC-F3 was suggested.

\subsubsection{Volumetric properties of fractions IEC-F1 and IEC-F2}

The volumetric properties (e.g. partial specific volume and partial specific adiabatic compressibility coefficient) can be related to solventsolute interactions and have been used to predict the structure and flexibility of macromolecules (Gekko \& Hasegawa, 1986; Gekko \& Yamagami, 1991; Hoiland, 1986). The partial specific volume $\left(\mathrm{v}_{\mathrm{s}}{ }^{\circ}\right)$ is defined as the change of the system volume due to the addition of an infinitesimal amount of the solute (Gekko \& Hasegawa, 1986; Gekko \& Yamagami, 1991; Hoiland, 1986; Mejia Tamayo et al., 2018) and can be determined from the following relationship:

$\mathrm{v}_{\mathrm{s}}^{\circ}=\frac{1}{\rho_{0}} \lim _{\mathrm{c} \rightarrow 0} \frac{\rho-\rho_{\mathrm{o}}}{\mathrm{C}}$

where: $\rho_{\mathrm{o}}$ and $\rho$ are the density of the solvent and dispersion, $\mathrm{C}$ is the concentration of the solute.

The partial adiabatic compressibility coefficient $\left(\beta_{\mathrm{s}}{ }^{\circ}\right)$ is defined as the change of the system pressure caused by the addition of an infinitesimal amount of the solute. It can be determined from density and sound velocity of the dispersion using the following expression (Gekko \& Hasegawa, 1986; Gekko \& Yamagami, 1991; Hoiland, 1986; Mejia Tamayo et al., 2018):

$\beta_{\mathrm{s}}^{\circ}=\left(\frac{\beta_{\mathrm{so}}}{\mathrm{V}_{\mathrm{s}}{ }^{\circ}}\right) \lim _{\mathrm{c} \rightarrow 0}\left[\frac{\beta / \beta_{\mathrm{so}}-\Phi}{\mathrm{C}}\right]$

where: $\beta$ and $\beta_{\text {so }}$ are the adiabatic compressibilities of the dispersion and solvent and $\Phi$ is the apparent specific volume $\left(\Phi=(\rho-C) / \rho_{o}\right)$. The adiabatic compressibility can be determined using the Newton Laplace equation: $\beta=\frac{1}{\mathrm{pu}^{2}}$.

Both properties depend mainly on the intrinsic contribution of the solute and its hydration. The first one refers to the constitutive volume of the molecule itself: the atoms forming the molecule (van der Waals volume) and the cavities formed in the interior of the molecule due to imperfect packing and hydrophobicity of the molecule. The hydration contribution refers to the solute-solvent interactions due to changes in physicochemical properties of interacting water molecules. Changes in $\mathrm{v}_{\mathrm{s}}{ }^{\circ}$ and $\beta_{\mathrm{s}}{ }^{\circ}$ are attributed to changes in the cavities or hydration. The first one has a positive effect on $\mathrm{v}_{\mathrm{s}}{ }^{\circ}$, suggesting a more flexible structure. Conversely, the second one has a negative effect on $v_{s}^{\circ}$, suggesting a less flexible structure (Chalikian \& Breslauer, 1996; Gekko \& Noguchi, 1979). 
Table 6

Partial specific volume $\left(\mathrm{v}_{\mathrm{s}}{ }^{\circ}\right)$ and partial specific adiabatic compressibility $\left(\beta_{\mathrm{s}}{ }^{\circ}\right)$ of Acacia senegal gum (Asen) and fractions HIC-F2, HIC-F3, IEC-F1, IEC-F2 and IEC-F1T.

\begin{tabular}{lll}
\hline & $\mathrm{v}_{\mathrm{s}}{ }^{\circ}\left(\mathrm{cm}^{3} \cdot \mathrm{g}^{-1}\right)$ & $\beta_{\mathrm{s}}{ }^{\circ}\left(\mathrm{x} 10^{11} \mathrm{~Pa}^{-1}\right)$ \\
\hline Asen $^{\text {a }}$ & 0.5842 & -12.2 \\
HIC-F2 $^{\text {a }}$ & 0.5876 & -14.4 \\
HIC-F3 $^{\text {a }}$ & 0.6500 & -1.0 \\
IEC-F1 $^{\text {IEC-F2 }}$ & 0.6095 & -9.42 \\
IEC-F1T $^{\text {b }}$ & 0.5823 & -12.9 \\
& 0.6313 & -5.0
\end{tabular}

a Values taken from Mejia Tamayo et al. (2018).

b Calculated considering that IEC-F1 is composed by $70 \%$ of HIC-F3 and $30 \%$ of $\mathrm{HIC}-\mathrm{F} 2$.

The volumetric properties, $\mathrm{v}_{\mathrm{s}}{ }^{\circ}$ and $\beta_{\mathrm{s}}{ }^{\circ}$, of the IEC-F1 and IEC-F2 fractions are presented in Table 6. IEC-F1 presented higher values of $\mathrm{v}_{s}^{\circ}$ and $\beta_{\mathrm{s}}{ }^{\circ}\left(0.6095 \mathrm{~cm}^{3} \mathrm{~g}^{-1}\right.$ and $-9.42 \times 10^{-11} \mathrm{~Pa}^{-1}$, respectively) than the IEC-F2 fraction $\left(0.5823 \mathrm{~cm}^{3} \mathrm{~g}^{-1}\right.$ and $-12.9 \times 10^{-11} \mathrm{~Pa}^{-1}$, respectively). Furthermore, using the reported values of the HIC-F1 and HIC-F2 fractions reported and assuming that IEC-F1 is composed of $70 \%$ HIC-F3 and 30\% HIC-F2, the theoretical partial specific volume $\left(\mathrm{v}_{\mathrm{ST}}{ }^{\circ}\right)$ and partial specific adiabatic compressibility $\left(\beta_{\mathrm{ST}}{ }^{\circ}\right)$ were calculated. Both, $\mathrm{V}_{\mathrm{ST}}^{\circ}$ and $\beta_{\mathrm{sT}}^{\circ}$ are higher than the experimental ones $\left(0.6313 \mathrm{~cm}^{3} \mathrm{~g}^{-1}\right.$ and $-5 \times 10^{-11} \mathrm{~Pa}^{-1}$, respectively). The differences between the theoretical and experimental $\mathrm{v}_{\mathrm{s}}^{\circ}$, can be explained due to the presence of supramolecular assemblies on IEC-F1 as it was evidenced using size exclusion chromatography (HPSEC-MALLS) and dynamic light scattering (DLS). Interestingly, both $\mathrm{v}_{\mathrm{s}}{ }^{\circ}$ and $\beta_{\mathrm{s}}{ }^{\circ}$ are higher than the values previously reported for Asen by Mejia Tamayo et al. (2018) $\left(0.584 \mathrm{~cm}^{3} \mathrm{~g}^{-1}\right.$ and $-12.2 \times 10^{-11} \mathrm{~cm}^{3} \mathrm{~g}^{-1}$, respectively). Since, the fraction IEC-F1 is mainly formed of the HIC-F2 and HIC-F3 fractions, which are less hydrated and more flexible molecules, the results are consistent with a more flexible and less hydrated structure. Furthermore, since protein interfacial properties have been clearly related to their molecule flexibility (Gekko \& Yamagami, 1991) and based on their partial specific volume, $\mathrm{v}_{\mathrm{s}}^{\circ},\left(0.588\right.$ and $0.650 \mathrm{~cm}^{3} \mathrm{~g}^{-1}$, respectively), these fractions have better interfacial properties. It is expected then that fraction IEC-F1 will have better interfacial properties compared to Asen, thus better foaming and emulsifying properties (Damodaran, 2008). All these results, and knowing that IEC-F1 exhibits a composition close to those from HIC-F2 and HIC-F3, are in coherence with the data previously reported by Mejia Tamayo et al. (2018). These authors found that HIC-F2 and HIC-F3 were the less polar AGP, according to its HIC elution order and protein content. Therefore, IEC-F1 will be able to bind less water molecules, and consequently will have a less hydrated and more flexible structure than HIC-F1.

\section{Conclusions}

We have achieved to obtain a fraction rich in aggregates from Asen gum through ion exchange chromatography using DEAE Sephacel gel as stationary phase. As expected, and according to Yariv detection, the two obtained fractions belong to AGP family, being called fraction IECF1 and fraction IEC-F2. We have thoroughly characterized the fraction IEC-F1, which presents similarities with both "classical" fractions HIC-F2 and HIC-F3. From the amino acid composition, we have estimated that fraction IEC-F1 corresponds theoretically to $70 \%$ of HIC-F3 and $30 \%$ of HIC-F2, and we have calculated the composition of a theoretical fraction named IEC-F1T. Significant differences between the molar mass distribution, the $\mathrm{M}_{\mathrm{w}}$ and $\mathrm{M}_{\mathrm{n}}$ values and the intrinsic viscosity of IEC-F1 fraction and those calculated for IEC-F1T were observed. We have also found high value for the $R_{g}$ parameter of fraction IEC-F1. Similarly, the results of Mark-Houwink-Sakurada
(MHS) analysis for fraction IEC-F1 show a low hydrodynamic coefficient value. All these experimental data obtained in IEC-F1 fraction, as well as its observed differences with the theoretical IEC-F1T calculated fraction were clearly attributed to the gain of aggregates. Moreover, from the hydrodynamic radius, further self-aggregation induced by the presence of HIC-F2 and HIC-F3 can also be deduced. Finally, the theoretical partial specific volume and partial specific adiabatic compressibility of fraction IEC-F1T were different from the experimental ones, which can be likewise explained due to the presence of supramolecular assemblies on IEC-F1. Summarizing, our results indicate a great tendency of fraction IEC-F1 to aggregate. The enrichment of naturally occurring aggregates together with the additional aggregation phenomena supported by the particular IEC conditions caused the mentioned gain of aggregates.

\section{Conflict of interest}

The authors declare that they have no conflict of interest.

\section{Compliance with ethics requirements}

This article does not contain any studies with human or animal subjects.

\section{Acknowledgements}

Author R. Apolinar-Valiente is the holder of a postdoctoral fellowship from ALLAND \& ROBERT Company -Natural and organic gums (Port Mort, France). This work was made possible by its financial assistance and is included within the DIVA research programme.

\section{References}

Aerts, J. (1998). Prediction of intrinsic viscosities of dendritic, hyperbranched and branched polymers. Computational and Theoretical Polymer Science, 8, 49-54.

Akiyama, Y., Eda, S., \& Kato, K. (1984). Gum Arabic is a kind of Arabinogalactan-Protein. Agricultural and Biology Chemistry, 48(1), 235-237.

Al-Assaf, S., Phillips, G. O., Aoki, H., \& Sasaki, Y. (2007). Characterization and properties of Acacia senegal (L.) willd. Var. Senegal with enhanced properties (Acacia (sen) SUPER GUM $\left({ }^{\mathrm{TM}}\right)$ ): Part 1-controlled maturation of Acacia senegal var. Senegal to increase viscoelasticity, produce a hydrogel form and convert a poor into a good emulsifier. Food Hydrocolloids, 21(3), 319-328.

Al-Assaf, S., Phillips, G. O., \& Williams, P. A. (2005). Studies on Acacia exudate gums: Part II. Molecular weight comparison of the vulgares and gummiferae series of Acacia gums. Food Hydrocolloids, 19(4), 661-667.

Al-Assaf, S., Sakata, M., McKenna, C., Aoki, H., \& Phillips, G. O. (2009). Molecular as sociations in Acacia gums. Structural Chemistry, 20(2), 325-336.

Apolinar-Valiente, R., Williams, P., Mazerolles, G., Romero-Cascales, I., Gómez-Plaza, E., López-Roca, J. M., et al. (2014). Effect of enzyme additions on the oligosaccharide composition of Monastrell red wines from four different wine-growing origins in Spain. Food Chemistry, 156, 151-159.

Bai, L., Liu, F., Xu, X., Huan, S., Gu, J., \& Julian, D. (2017). Impact of polysaccharide molecular characteristics on viscosity enhancement and depletion flocculation. Journal of Food Engineering, 207, 35-45.

Bello-Pérez, L. A., Roger, P., Colonna, P., \& Paredes-López, O. (1998). Laser light scattering of high amylose and high amylopectin materials, stability in water after microwave dispersion. Carbohydrate Polymers, 37, 383-394.

Burchard, W. (1999). Solution properties of branched macromolecules. Advances in Polymer Science, 143, 113-194.

Callaghan, P. T., \& Lelievre, J. (1985). The size and shape of amylopectin: A study using pulsed field gradient nuclear magnetic resonance. Biopolymers, 24(3), 441-460.

Callaghan, P. T., Lelievre, J., \& Lewis, J. A. (1987). A comparison of the size and shape of b-limit dextrin and amylopectin using pulsed field-gradient nuclear magnetic resonance and analytical ultracentrifugation. Carbohydrate Research, 162, 33-40.

Castellani, O., Guibert, D., Al-Assaf, S., Axelos, M., Phillips, G. O., \& Anton, M. (2010). Hydrocolloids with emulsifying capacity. Part 1 - emulsifying properties and interfacial characteristics of conventional (Acacia senegal (L.) Willd. var. Senegal) and matured (Acacia (sen) SUPER GUM ${ }^{\mathrm{TM}}$ ) Acacia senegal. Food Hydrocolloids, 24(2-3), 193-199.

Chalikian, T. V., \& Breslauer, K. J. (1998). Thermodynamic analysis of biomolecules: A volumetric approach. Current Opinion in Structural Biology, 8, 657-664.

Chikamai, B. N., Banks, W. B., Anderson, D. M. W., \& Weiping, W. (1996). Processing of gum Arabic and some new opportunities. Food Hydrocolloids, 10(3), 309-316.

Damodaran, S. (2008). Amino acids, peptides and proteins. In S. Damodaran, K. L. Parkin, \& O. R. Fennema (Eds.). Fennema's food chemistry (pp. 217-329). Boca Raton: CRC 
Press.

Dickinson, E. (2003). Hydrocolloids at interfaces and the influence on the properties of dispersed systems. Food Hydrocolloids, 17(1), 25-39.

Doco, T., O'Neill, M. A., \& Pellerin, P. (2001). Determination of the neutral and acidic glycosyl residue compositions of plant cell polysaccharides by GC-EI-MS analysis of the trimethylsilyl methyl glucoside derivatives. Carbohydrate Polymers, 46, 249-259.

Dror, Y., Cohen, Y., \& Yerushalmi-Rozen, R. (2006). Structure of gum Arabic in aqueous solution. Journal of Polymer Science Part B: polymer Physics, 44(22), 3265-3271.

Dumay, E., Picart, L., Regnault, S., \& Thiebaud, M. (2006). High pressure-low temperature processing of food proteins. Biochimica et Biophysica Acta, 1764, 599-618.

Ferreira, R. B., Freitas, R. L., \& Teixeira, A. R. (2003). Self-aggregation of legume seed storage proteins inside the protein storage vacuoles is electrostatic in nature, rather than lectin-mediated. FEBS Letters, 534(1-3), 106-110.

Gashua, I. B., Williams, P. A., \& Baldwin, T. C. (2016). Molecular characteristics, association and interfacial properties of gum Arabic harvested from both Acacia senegal and Acacia seyal. Food Hydrocolloids, 61, 514-522.

Gashua, I. B., Williams, P. A., Yadav, M. P., \& Baldwin, T. C. (2015). Characterization and molecular association of Nigerian and Sudanese Acacia gum exudates. Food Hydrocolloids, 51, 405-413.

Gekko, K., \& Hasegawa, Y. (1986). Compressibility-structure relationship of globular proteins. Biochemistry, 25(21), 6563-6571.

Gekko, K., \& Noguchi, H. (1979). Compressibility of globular proteins in water at $25^{\circ} \mathrm{C}$. Journal of Physical Chemistry, 83(21), 2706-2714.

Gekko, K., \& Yamagami, K. (1991). Flexibility of food proteins as revealed by compressibility. Journal of Agricultural and Food Chemistry, 39(1), 57-62.

Gleeson, P. A., \& Jermyn, M. A. (1979). Alteration in the composition of -lectins caused by chemical and enzymic attack. Australian Journal of Plant Physiology, 6, 25-30.

Hoiland, H. (1986). Partial molar volumes of biochemical model compounds in aqueous solution. In H.-J. HINZ (Ed.). Thermodynamic data for biochemistry and biotechnology. Springer-Verlag Berlin Heidelberg.

Idris, O. H. M., Williams, P. A., \& Phillips, G. O. (1998). Characterisation of gum from Acacia senegal trees of different age and location using multidetection gel permeation chromatography. Food Hydrocolloids, 12(4), 379-388.

Islam, A. M., Phillips, G. O., Sljivo, A., Snowden, M. J., \& Williams, P. A. (1997). A review of recent developments on the regulatory, structural and functional aspects of gum Arabic. Food Hydrocolloids, 11(4), 493-505.

Karamalla, K. A., Siddig, N. E., \& Osman, M. E. (1998). Analytical data for Acacia senegal var. Senegal gum samples collected between 1993 and 1995 from Sudan. Food Hydrocolloids, 12, 373-378.

Lamport, D. T. A., \& Várnai, P. (2013). Periplasmic arabinogalactan glycoproteins act as a calcium capacitor that regulates plant growth and development. New Phytologist, 197, $58-64$.

Lelievre, J., Lewis, J. A., \& Marsden, K. (1986). The size and shape of amylopectin: A study using analytical ultracentrifugation. Carbohydrate Research, 153(2), 195-203.

Li, X., Fang, Y., Al-assaf, S., Phillips, G. O., Nishinari, K., \& Zhang, H. (2009). Rheological study of gum Arabic solutions: Interpretation based on molecular self-association. Food Hydrocolloids, 23(8), 2394-2402.

Li, L., Lu, Y., An, L., \& Wu, C. (2013). Experimental and theoretical studies of scaling of sizes and intrinsic viscosity of hyperbranched chains in good solvents. The Journal of Chemical Physics, 138(11), 114908.

Lopes, L., Andrade, C. T., Milas, M., \& Rinaudo, M. (1995). Influence of aggregates on the sedimentation properties of welan gum: The velocity of the particle sedimentation is affected by the type and size of the aggregates. Polymer Bulletin, 34(5-6), 655-662.

Lopez-Torrez, L., Nigen, M., Williams, P., Doco, T., \& Sanchez, C. (2015). Food Hydrocolloids Acacia senegal vs . Acacia seyal gums - Part 1: Composition and structure of hyperbranched plant exudates. Food Hydrocolloids, 51, 41-53.

Mahendran, T., Williams, P. A., Phillips, G. O., Al-Assaf, S., \& Baldwin, T. C. (2008). New insights into the structural characteristics of the arabinogalactan - protein (AGP) fraction of gum Arabic. Journal of Agricultural and Food Chemistry, 56, 9269-9276.

Manning, H. E., \& Bird, M. R. (2015). Gum Arabic fractionation using synthetic membranes: The importance of fouling. Food and Bioproducts Processing, 93, 298-303.

Mejia Tamayo, V., Nigen, M., Apolinar-Valiente, R., Doco, T., Williams, P., Renard, D., et al. (2018). Flexibility and hydration of amphiphilic hyperbranched arabinogalactan-protein from plant Exudate: A volumetric perspective. Colloids and Interfaces, $2,11$.

Millard, M. M., Dintzis, F. R., Willett, J. L., \& Klavons, J. A. (1997). Light-scattering molecular weights and intrinsic viscosities of processed waxy maize starches in $90 \%$ dimethyl sulfoxide and H2O. Cereal Chemistry, 74(5), 687-691.

Mothe, C. G., \& Rao, M. A. (1999). Rheological behavior of aqueous dispersions of cashew gum and gum Arabic: Effect of concentration and blending. Food Hydrocolloids, 13(6), 501-506.

Mudgil, D., Barak, S., \& Khatkar, B. S. (2012). Effect of enzymatic depolymerization on physicochemical and rheological properties of guar gum. Carbohydrate Polymers, 90(1), 224-228.

Nieto, P. M. (2014). Funcionalizing carbohydrates for food applications. In E. Milda, Embuscado, McCormick, \& I. Company (Eds.). Gum polysaccharides as texturizing systems (pp. 81-253). Lancaster, Pennsylvania, USA: DEStech Publications Inc.

Nie, S., Wang, C., Cui, S. W., Wang, Q., Xie, M., \& Phillips, G. O. (2013). The core carbohydrate structure of Acacia seyal var. seyal (Gum Arabic). Food Hydrocolloids, $32(2), 221-227$.

Nussinovitch, A. (2009). Plant gum exudates of the word. Sources, distribution, properties and applications. Physiological aspects of polysaccharide formation in plants (pp. 2339). Boca Raton, USA: CRC Press, Taylor \& Francis Group.

Osman, M. E., Menzies, A. R., Martin, B. A., Williams, P. A., Phillips, G. O., \& Baldwin, T. C. (1995). Characterization of gum Arabic fractions obtained by anion-exchange chromatography. Phytochemistry, 38, 409-417.

Osman, M. E., Menzies, A. R., Williams, P. A., Phillips, G., \& Baldwin, T. C. (1993). The molecular characterisation from Acacia Senegal of the polysaccharide gum. Carbohydrate Polymers, 246, 303-318.

Paulsen, B. S., Craik, D. J., Dunstan, D. E., Stone, B. A., \& Bacic, A. (2014). The Yariv reagent: Behaviour in different solvents and interaction with a gum Arabic arabinogalactanprotein. Carbohydrate Polymers, 106(1), 460-468.

Pickles, N. A., Aoki, H., Al-Assaf, S., Sakata, M., Ogasawara, T., Ireland, H. E., et al (2007). Characterisation and properties of Acacia senegal (L.) willd. Var, Senegal with enhanced properties (Acacia (sen) SUPER GUM ${ }^{\mathrm{TM}}$ ): Part 3 immunological characterisation of Acacia (sen) SUPER GUM ${ }^{\mathrm{TM}}$. Food Hydrocolloids, 21, 338-346.

Qian, H. F., Cui, S. W., Wang, Q., Wang, C., \& Zhou, H. M. (2011). Fractionation and physicochemical characterization of peach gum polysaccharides. Food Hydrocolloids, $25,1285-1290$.

Qi, W., Fong, C., \& Lamport, D. T. A. (1991). Gum Arabic glycoprotein is a twisted hairy rope. Plant Physiology (Bethesda), 96(3), 848-855.

Randall, R. C., Phillips, G. O., \& Williams, P. A. (1989). Fractionation and characterization of gum from Acacia senegal. Food Hydrocolloids, 3(1), 65-75.

Ray, A. K., Bird, P. B., Iacobucci, G. A., \& Clark, B. C. (1995). Functionality of gum Arabic Fractionation, characterization and evaluation of gum fractions in citrus oil emulsions and model beverages. Food Hydrocolloids, 9(2), 123-131.

Renard, D., Garnier, C., Lapp, A., Schmitt, C., \& Sanchez, C. (2012). Structure of arabinogalactan-protein from Acacia gum : From porous ellipsoids to supramolecular architectures. Carbohydrate Polymers, 90(1), 322-332.

Renard, D., Lavenant-Gourgeon, L., Lapp, A., Nigen, M., \& Sanchez, C. (2014b). Enzymatic hydrolysis studies of arabinogalactan-protein structure from Acacia gum: The self-similarity hypothesis of assembly from a common building block. Carbohydrate Polymers, 112, 648-661.

Renard, D., Lavenant-Gourgeon, L., Ralet, M.-C., \& Sanchez, C. (2006). Acacia senegal gum: Continuum of molecular species differing by their protein to sugar ratio, molecular weight, and charges. Biomacromolecules, 7(9), 2637-2649.

Renard, D., Lepvrier, E., Garnier, C., Roblin, P., Nigen, M., \& Sanchez, C. (2014a) Structure of glycoproteins from Acacia gum: An assembly of ring-like glycoproteins modules. Carbohydrate Polymers, 99, 736-747.

Robinson, G., Ross-Murphy, S. B., \& Morris, E. R. (1982). Viscosity-molecular weight relationships, intrinsic chain flexibility, and dynamic solution properties of guar galactomannan. Carbohydrate Research, 107, 17-32.

Rolland-Sabaté, A., Mendez-Montealvo, M. G., Colonna, P., \& Planchot, V. (2008). Online determination of structural properties and observation of deviations from power law behavior. Biomacromolecules, 9(7), 1719-1730.

Ross-Murphy, S. B. (1994). In S. B. Ross-Murphy (Ed.). Physical techniques for the study of food biopolymers (pp. 342-392). Blackie Academic \& Professional.

Sanchez, C., \& Renard, D. (2002). Stability and structure of protein-polysaccharide coacervates in the presence of protein aggregates. International Journal of Pharmaceutics, 242(1-2), 319-324.

Sanchez, C., Nigen, M., Mejia Tamayo, V., Doco, T., Williams, P., Amine, C., et al. (2018). Acacia gum: History of the future. Food Hydrocolloids, 78, 140-160.

Sanchez, C., Renard, D., Robert, P., Schmitt, C., \& Lefebvre, J. (2002). Structure and rheological properties of Acacia gum dispersions. Food Hydrocolloids, 16(3), 257-267.

Sibaja-Hernández, R., Román-Guerrero, A., Sepúlveda-Jiménez, G., \& Rodríguez-Monroy M. (2015). Physicochemical, shear flow behaviour and emulsifying properties of Acacia cochliacantha and Acacia farnesiana gums. Industrial Crops and Products, 67, $161-168$.

Sims, I. M., \& Furneaux, R. H. (2003). Structure of the exudate gum from Meryta sinclairii. Carbohydrate Polymers, 52(4), 423-431.

Sommer-Knudsen, J., Bacic, A., \& Clarke, A. E. (1998). Hydroxyproline-rich plant glycoproteins. Phytochemistry, 47(4), 483-497.

Tan, L., Showalter, A. M., Egelund, J., Henandez-Sanchez, A., Doblin, M. S., \& Bacic, A. (2012). Arabinogalactan-proteins and the research challenges for these enigmatic plant cell surface proteoglycans. Frontiers of Plant Science, 3(140), 1-10.

Vandevelde, M.-C., \& Fenyo, J.-C. (1985). Macromolecular distribution of Acacia senegal gum. Carbohydrate Polymers, 5(203), 251-273.

Verbeken, D., Dierckx, S., \& Dewettinck, K. (2003). Exudate gums: Occurrence, production, and applications. Applied Microbiology and Biotechnology, 63(1), 10-21.

Yan, D., Gao, C., \& Frey, H. (2011). Hyperbranched polymers: Synthesis, properties, and applications. Hoboken, New Jersey: John Wiley \& Sons, Inc., Publication (Chapter 12).

Zhu, C., Gao, Y., Li, H., Meng, S., Li, L., Francisco, J. S., et al. (2016). Characterizing hydrophobicity of amino acid side chains in a protein environment via measuring contact angle of a water nonodroplet on planar peptide network. Proceedings of the National Academy of Sciences of the United States of America, 113, 12946-12951. 